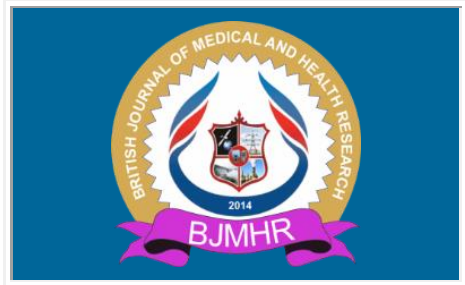

\title{
BJMHR
}

British Journal of Medical and Health Research

Journal home page: www.bjmhr.com

\section{Effect of Mulberry Leaf Extract on Clinical Isolated Pseudomonas aeruginosa Biofilm Formation}

\section{Khaemaporn Boonbumrung, ${ }^{1,2}$, Wanpen Chaicumpa ${ }^{3}$ \\ 1. Department of Transfusion Medicine and Clinical Microbiology, Faculty of Allied Health Sciences, Chulalongkorn University, Bangkok 10330, Thailand \\ 2. Research Unit of Innovative Diagnosis of Antimicrobial Resistance, Faculty of Allied Health Sciences, Chulalongkorn University, Bangkok 10330, Thailand \\ 3.Department of Parasitology, Faculty of Medicine Siriraj Hospital, Mahidol University, Bangkok 10700, Thailand}

\begin{abstract}
Pseudomonas aeruginosa is the most common Gram-negative bacteria that causes fatal nosocomial infections amongst hospitalized patients, especially immunocompromised subjects. The bacteria resist a wide variety of currently available antibiotics. One of the resistant mechanisms includes forming biofilms in the infected host, which prevents the accessibility of drugs to their respective bacterial cell targets. A novel strategy to overcome this antibiotic resistance mechanism is the use of antibiotics in combination with biofilm formation inhibitors. The objective of this study was to investigate the effect of mulberry-leaf extracts on $P$. aeruginosa biofilm formation. The results of specific biofilm formation (SBF) index evaluations showed that mulberry-leaf ethanolic $(256 \mu \mathrm{g} / \mathrm{ml})$ and ether extracts $(32 \mu \mathrm{g} / \mathrm{ml})$ presented strong capacities (SBF index > 1.1) to reduce biofilm formation by $44.0 \%$ and $44.8 \%$, respectively. Each plant extract anti-biofilm activity was tested further in combination with gentamicin $(0.125$ to $1,024 \mu \mathrm{g} / \mathrm{mL})$ using the checkerboard method; however, no synergistic efficacy was observed. The MBEC and CLSM results revealed that the ether extract $(32 \mu \mathrm{g} / \mathrm{ml})$ was effective against $P$. aeruginosa biofilm formation. This study should provide an alternative strategy for the effective treatment of deadly infections caused by the most common drug resistant bacteria, $P$. aeruginosa.
\end{abstract}

Keywords: Leaf Extracts, Mulberry, Pseudomonas aeruginosa, Biofilm

*Corresponding Author Email: khaemaporn.b@ chula.ac.th Received 15 May 2020, Accepted 25 May 2020

Please cite this article as: Boonbumrung $\mathrm{K}$ et al., Effect of Mulberry Leaf Extract on Clinical Isolated Pseudomonas aeruginosa Biofilm Formation. British Journal of Medical and Health Research 2020. 


\section{INTRODUCTION}

Infectious disease incidence rates have increased in many countries worldwide. Additionally, higher mortality rates are found in immunocompromised, elderly and chronically infected patients, especially in cases in which catheter or implanted medical devices were involved ${ }^{1}$. These infections include Pseudomonas aeruginosa, which is the most common Gram-negative bacteria that causes fatal nosocomial infections amongst hospitalized patients, particularly immunocompromised subjects ${ }^{2,3}$. The mortality rates related to pseudomonad bacteremia have been reported to range from $18 \%$ to $62 \%{ }^{4}$. These bacteria have been found to be the pathogens most related to nosocomial infection $(13.4 \%)$ in Thailand ${ }^{5}$. Clinical P. aeruginosa strain antibiotic resistance was found to be significantly correlated with increased consumption of anti-pseudomonad drugs, such as extended-spectrum cephalosporins, carbapenems, fluoroquinolones and aminoglycosides ${ }^{6}$. The resistance to a wide variety of currently available antibiotics places these bacteria under selective pressure ${ }^{7}$. There are many mechanisms by which organisms act to resist antimicrobial agents, such as modifying enzymes, energyrequiring membrane efflux pumps and preventing cell exposure by forming biofilms ${ }^{8}$. Microbial biofilms cause serious medical problems because they resist antibiotics and the host immune response. By definition, a biofilm is a community of cells that are attached to either a biotic or abiotic surface and is enclosed in a complex exopolymeric substance ${ }^{9}$. Antibiotic susceptibility is reduced because of several mechanisms, including slower growth rates, altered metabolism, oxygen gradient differences, extracellular matrix changes, up-regulated stress proteins, the presence of bacterial persister cells and the spread of antibiotic resistance genes through the promotion of horizontal gene transfer ${ }^{10-12}$. Biofilm formation adds greater resistance to deleterious agents, such as antibiotics, sanitizers and disinfectants ${ }^{13}$. Novel strategies to overcome these antibiotic resistance mechanisms include the use of antibiotics in combination with biofilm formation inhibitors ${ }^{14}$.

Plant-derived compounds have gained widespread interest in identifying microbial control alternatives ${ }^{15}$. Most studies regarding natural compounds have focused on the effects of these compounds against planktonic bacteria, with a rare emphasis on the biofilm forms that are more resistant to antimicrobial agents and are very difficult to eradicate. Novel compounds from baicalin, which is extracted from Scutellaria baicalensis and ajoene (a sulfur-rich molecule from garlic), have been presented to eradicate P. aeruginosa biofilm formation ${ }^{16,17}$. In Asian countries, mulberry (Morus alba) leaves are used as infusions and medicinal herbs due to their enrichment in flavonoids, amino acids, vitamins and other trace elements ${ }^{18}$. This herb has been described to have antioxidant, anti-hyperglycemic, anti-hyperlipidemic, antihypertension and antibacterial activities ${ }^{19-21}$. The recently identified 1-deoxynojirimycin from mulberry leaves 
was shown to inhibit Streptococcus mutans biofilm formation by preventing surface adherence, which is required for biofilm formation ${ }^{22}$. However, the effect of this herb on biofilms that are produced by other Gram-negative bacteria is still unknown. This study investigated the effect of the mulberry leaf on Pseudomonas aeruginosa biofilm formation. We also utilized the synergy test to combine mulberry leaf extractions with antibiotics for alternative treatments of $P$. aeruginosa biofilm formation.

\section{MATERIALS AND METHOD}

\section{Bacterial strains}

One hundred thirty-six bacterial strains of clinically isolated Pseudomonas aeruginosa were collected from Rajavithi Hospital, Bangkok, Thailand in 2009. Four specimen types were collected, including blood (2.9\%), urine (25.7\%), sputum (41.9\%) and pus (29.5\%). Biochemical tests were performed to identify P. aeruginosa, including Gram staining, oxidase testing, carbohydrate utilization, growth at $42^{\circ} \mathrm{C}$ and motility. P. aeruginosa was cultured on Muller Hinton agar (Oxoid) at $37^{\circ} \mathrm{C}$ overnight.

\section{Plant extract preparation}

White mulberry (Morus alba L., Moraceae) were collected from Nan province at the northern of Thailand, during 2012. The samples were identified and authenticated by specialist from Department of Agricultural, Bangkok Thailand and the voucher specimens (BK067671/SB.002/Chiang Mai) were deposited at the Bangkok Herbarium (BK) at Department of Agricultural in Bangkok Thailand. The mulberry leaves were washed and dried in an oven at $67^{\circ} \mathrm{C}$ for $6 \mathrm{~h}$. The dried leaves were ground with an electronic mixer and then sieved. Three sample types were suspended in ethanol, hexane and diethyl ether at 1:10 ratios and then subjected to ultrasonic extraction for $3 \mathrm{~h}$. All crude extracts were filtered and evaporated under vacuum control. The samples were stored at $-20^{\circ} \mathrm{C}$ and protected from direct light until they were tested for antibacterial and anti-biofilm activity.

\section{Determining the crude extract MICs}

The minimal inhibitory concentration (MIC) was determined using the microdilution broth method, which was followed by CLSI ${ }^{23}$. A two-fold serial dilution of the crude extracts $(2.048$ $\mathrm{mg} / \mathrm{mL}-4 \mu \mathrm{g} / \mathrm{mL}$ ) was prepared using Mueller Hinton Broth (MHB) (Oxoid, UK) as a diluent. The antibiotics were tested in parallel with serial gentamicin $(512-1 \mu \mathrm{g} / \mathrm{mL})$ and ciprofloxacin $(168-0.328 \mu \mathrm{g} / \mathrm{mL})$ dilutions. One hundred extracted dilutions, plus an antimicrobial solution and medium diluent as a negative control, were added to 96-well sterile microplate wells. Each dilution was inoculated with $100 \mu \mathrm{L}$ of each bacterial test strain, which were adjusted to $5 \times 10^{6}$ $\mathrm{cfu} / \mathrm{mL}$ with fresh MHB. After incubation at $37^{\circ} \mathrm{C}$ for $24 \mathrm{~h}$, bacterial growth was indicated by assessing for visible growth of the test strains. The MIC was determined in separate duplicate 
samples, by observing the last crude extract concentration at which bacterial growth was not found.

\section{Combined gentamicin activity evaluations with the checkerboard technique}

The interactive activity of gentamicin with the ether-extracted mulberry leaves against both intermediate (50122) and resistant (50483) $P$. aeruginosa strains was evaluated with the broth microdilution checkerboard method ${ }^{24}$. The gentamicin and mulberry leaf extract concentrations used were $0.5-256 \mu \mathrm{g} / \mathrm{mL}$ and $8-512 \mu \mathrm{g} / \mathrm{mL}$, respectively. Briefly, $50 \mu \mathrm{L}$ of CAMHB was dispended into each well of the 96-microwell plates. Then, the gentamicin was serially diluted along the rows (1-11), while the extract was diluted along the columns (B-H). To test each substance individually, only gentamicin was serially diluted in row 12 , and only the mulberry leaf extracts were diluted in column A. The bacterial inoculum for each bacterial strain was prepared in CAMHB at $5 \times 10^{6} \mathrm{cfu} / \mathrm{mL}$; then, $100 \mu \mathrm{L}$ was added to each well and incubated at $37^{\circ} \mathrm{C}$ for $24 \mathrm{~h}$. To determine the MIC results, the lowest gentamicin and extract concentration that completely inhibited the bacterial growth was observed by naked eye. The fractional inhibitory concentration (FIC) index were calculated as follows: FIC index $=$ FIC of gentamicin (A) + FIC of extract (B), where FIC A is the MIC of gentamicin in the combination/MIC of gentamicin alone, and FIC B is the MIC of the extract in the combination/MIC of the extract alone. The combination was considered synergistic when the FIC index was $\leq 0.5$, indifferent when the FIC index was $>0.5$ to $<4.0$, and antagonistic when the FIC index was $\geq 4.0$.

\section{The specific biofilm formation assay and the anti-biofilm screening test}

A static biofilm formation assay was performed in 96-well polystyrene plates (Nunc, United States), as described previously ${ }^{25}$ with a few modifications. Briefly, P. aeruginosa was inoculated into $\mathrm{MHB}$ at $37^{\circ} \mathrm{C}$ for $24 \mathrm{~h}$; then, the cells were washed with $0.85 \%$ NSS and adjusted to $5 \times 10^{6} \mathrm{cfu} / \mathrm{mL}$. One hundred microliters of the tested strains was cultured in $96-$ microwell plates with or without the plant extracts for $24 \mathrm{~h}$ without shaking. Biofilm formation was evaluated by staining with a crystal violet solution $(0.1 \%)$ for $15 \mathrm{~min}$; the excess staining was washed three times with PBS; then, the bounded biofilms were dried at room temperature for $30 \mathrm{~min}$ and subsequently dissolved in $95 \%$ methanol before measuring the absorbance at $570 \mathrm{~nm}$. The cell growth in the 96-well plates was also measured at $\mathrm{OD}_{620 \mathrm{~nm}}$. The SBF index was determined by applying the following formula: $\mathrm{SBF}$ index $=(\mathrm{AB}-\mathrm{CW}) / \mathrm{G}$, in which $\mathrm{AW}$ was the $\mathrm{OD}_{570 \mathrm{~nm}}$ of the stained attached bacteria, $\mathrm{CW}$ was the $\mathrm{OD}_{570 \mathrm{~nm}}$ of stained control wells as abiotic factors and $\mathrm{G}$ was the $\mathrm{OD}_{620 \mathrm{~nm}}$ of cell growth in suspension. The assays were performed separately in triplicate.

\section{The effect of the mulberry leaf extract on biofilm formation}


The antimicrobial susceptibility testing of the biofilms was based on a previously described technique, with modifications ${ }^{26}$. The bacterial inoculum was prepared, as described earlier, in 96-well microplates (Nunc, United States) and covered with lids with 96 pegs (Transferable Solid Phase, TSP; Nunc). These plates were incubated at $37^{\circ} \mathrm{C}$ for $24 \mathrm{~h}$, which resulted in the build-up of biofilms that surrounded the pegs. The planktonic cells were washed from the pegged lid with the biofilms using three PBS washes. The pegs were transferred to a test plate with different mulberry leaf extract concentrations $(256-2 \mu \mathrm{g} / \mathrm{mL})$, which was called the challenge plate. The challenge plates were incubated at $37^{\circ} \mathrm{C}$ for $24 \mathrm{~h}$; then, the pegs were rinsed with PBS three times to clean the remaining extract. These pegs were used to quantify the amount of biofilm remaining after the extract treatments with the crystal violet staining method described earlier. The other pegs were used to enumerate the viable bacteria after testing by sonication at $40 \pm 2 \mathrm{kHz}$ and $0.22 \pm 0.04 \mathrm{~W} / \mathrm{cm}^{2}$ for $5 \mathrm{~min}$. The suspension was spread onto TSA medium for the plate count technique. The bacterial survival rates were reported using the following calculation: \% survival $=[($ remaining $\mathrm{cfu} / \mathrm{mL}$ after exposure $) /$ (initial $\mathrm{cfu} / \mathrm{mL})] \mathrm{x} 100$. All of the tests were run in triplicate.

\section{Biofilm structure evaluations with a confocal laser scanning microscope (CLSM)}

The biofilm formation architecture was examined with a confocal laser scanning microscope (Zeiss, LSM 700, Germany) and analyzed with the COMSTAT program, which was kindly provided by Heydon et al. ${ }^{27}$. The biofilms were grown for $0,8,16$, and $24 \mathrm{~h}$ on coverslips (Lab-Tek II chamber slide with cover, Nunc, United States) and stained with Live/Dead (Syto9/PI) stain (Molecular probes, United States) according to the manufacturer's instructions. The CLSM images quantitative analyses were conducted using the image stacks mode with a minimum of seven different images per test at 1-2 $\mu \mathrm{M}$ depths from three independent experiments. Five parameters were assessed, including the biomass $\left(\mu \mathrm{M}^{3} / \mu \mathrm{M}^{2}\right)$, average thickness $(\mu \mathrm{M})$, rough coefficient, surface to biovolume ratio $\left(\mu \mathrm{M}^{2} / \mu \mathrm{M}^{3}\right)$, and maximum thickness $(\mu \mathrm{M})$.

\section{RESULTS AND DISCUSSION}

\section{Biofilm formation evaluations with the SBF index}

One hundred thirty-six $P$. aeruginosa clinical isolates were evaluated with crystal violet staining, and the biofilm production was semi-quantitatively classified into 4 types according to the following SBF indexes: strong $(\geq 1.10)$, moderate $(0.79 \geq x \geq 1.10)$, weak $(0.35 \geq x \geq 0.79)$ and negative $(\leq 0.35)$. Although, the bacterial biofilm formations involved many factors (e.g., culture conditions, strain and methodology) ${ }^{28}$, mathematical formulas were necessary to quantify the biofilm formations ${ }^{25}$. In this study, we used the SFB index to assess the biofilm producers and observed several biofilm-producing abilities (Figure 1). We found that most 
strains presented strong activity 59\% (80/136), and an equal amount presented with moderate and weak activity (10\%). Some of the tested strains (21\%) showed negative biofilm formation activities. This assay was suitable for biofilm production quantification in cases with numerous samples and various microbial strains ${ }^{29-31}$. There were a few studies regarding biofilm formation in clinical samples. In our study, 136 clinical $P$. aeruginosa isolates had the ability to produce biofilms (these were $79 \%$ of the total evaluated), which was similar to the results of a previous study, which reported $88.6 \%{ }^{32}$.

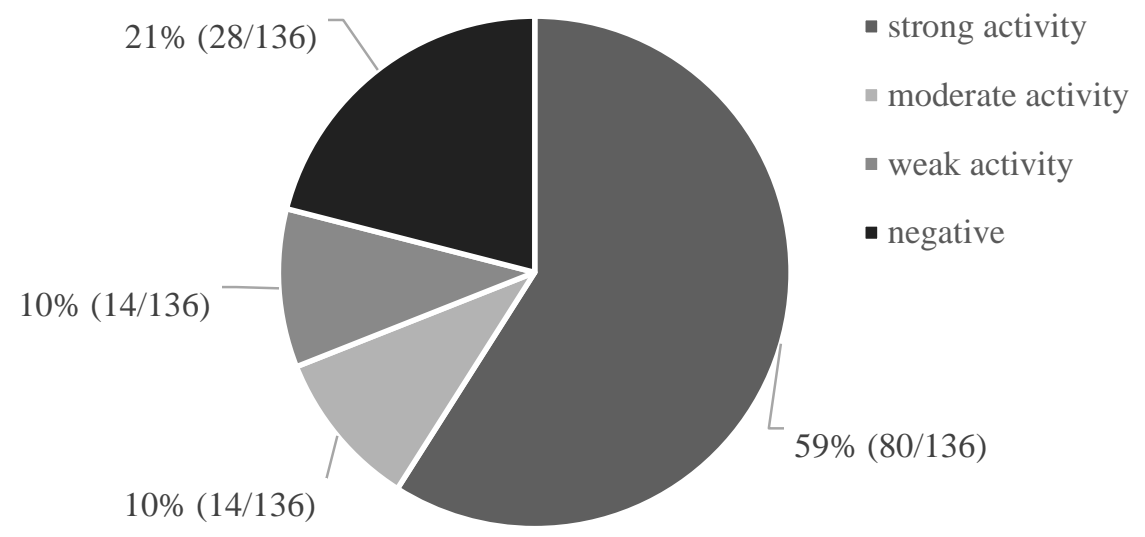

Figure 1: Biofilm formations of the 136 observed $P$. aeruginosa clinical isolates, which were classified as strong $(\mathrm{SBF}$ index $>1.1)$, moderate $(0.7>\mathrm{SBF}$ index $<1.1)$, weak $(0.35$ $>$ SBF index $<0.7$ ) and negative (SBF index < 0.35) biofilms.

\section{The effect of the mulberry leaf extracts on biofilm formation}

The ether, ethanol and hexane mulberry leaf extracts were tested with $P$. aeruginosa isolate cocultures. Biofilm activity comparisons between the controls (without extracts) and mulberry leaf extracts showed that the extracts dramatically reduced the biofilm producer numbers $(79 \%)$ to $50 \%$, especially the strong activity type producers (59\%), whose numbers were decreased to 24.5-29.6\% (Figure 2). This study highlights the capacity for mulberry leaf extracts to reduce the activity of biofilms that are produced from clinical $P$. aeruginosa isolates. 


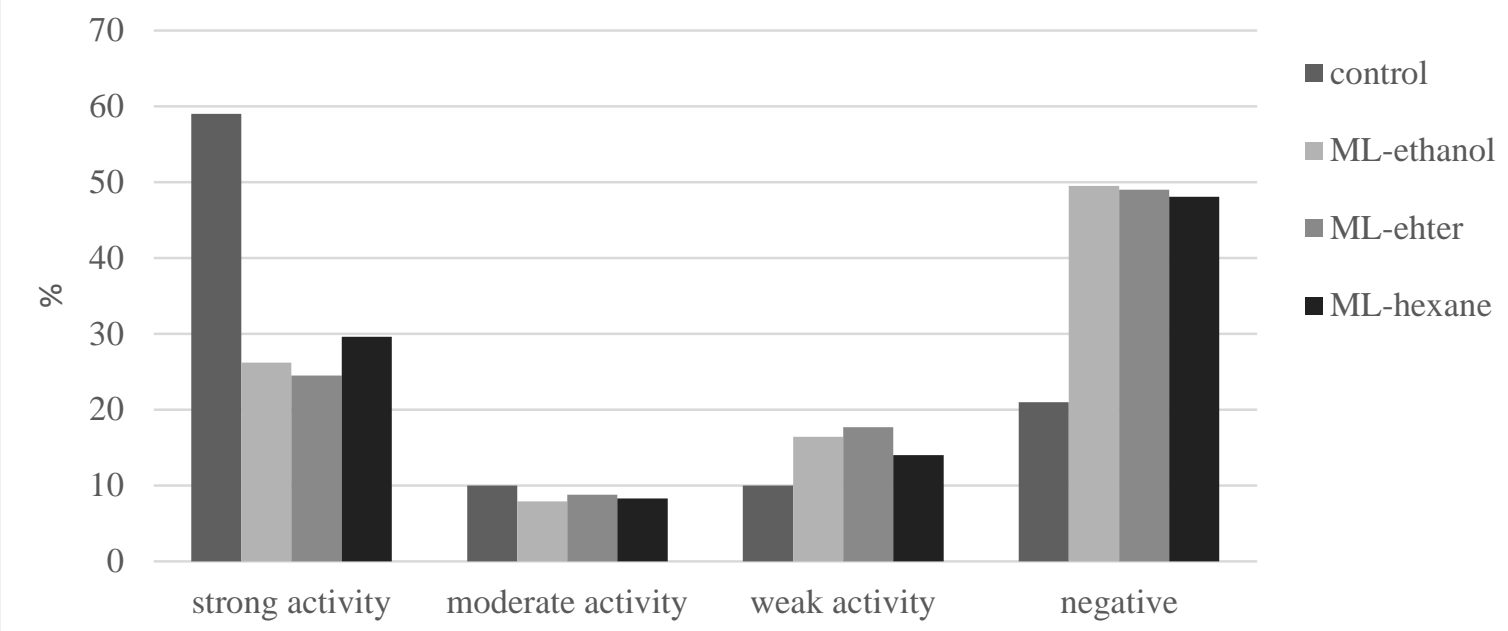

Figure 2: Percentage of biofilm-forming activity $\left(37^{\circ} \mathrm{C}, 24 \mathrm{~h}\right)$, based on SBF index. The activities were divided into 4 groups, including strong, moderate, weak and negative groups, after they were tested with the ethanol, ether and hexane mulberry extracts as compared with a control group (without extract).

\section{Antibacterial activity and synergy effect of mulberry leaf extract}

The crude mulberry leaf (4 to $2,048 \mu \mathrm{g} / \mathrm{mL}$ ) extract did not significantly inhibit the growth of any of the tested $(n=136)$ strains. Mulberry leaf extract and gentamicin combinations were tested on the $P$. aeruginosa 50122 and 50483 strains. The $P$. aeruginosa 50122 strain was an intermediate strain for gentamicin susceptibility with the disk diffusion method; however, the 50483 strain was gentamicin resistant. The MIC was retested in both, and the strain resistance was evaluated $(=8 \mu \mathrm{g} / \mathrm{mL})$. The MIC was reduced to $2 \mu \mathrm{g} / \mathrm{mL}$ in both strains with the gentamicin + extract. However, MBC of $P$. aeruginosa 50122 was found $(2 \mu \mathrm{g} / \mathrm{mL})$ regarding the bactericidal activity.



Figure 3 The effect of the ether mulberry leaf extracts at different concentrations ( 2 to $256 \mu \mathrm{g} / \mathrm{mL}$ ) on $P$. aeruginosa 50122 biofilm formation with co-culturing. 


\section{$P$. aeruginosa biofilm architecture and residence}

The bacterial cells inside the biofilm at $24 \mathrm{~h}$ were treated with the extracts by using MBEC. The extract could not be eradicated from the biofilm; however, it reduced the amounts of the biofilm and the resident cells inside the biofilm. The optimal concentration of the ether mulberry leaf extracts $(32 \mu \mathrm{g} / \mathrm{mL})$ is shown in Figure 3. These results indicate that the extract had an effect on the biofilm architecture by changing the biofilm surface and finally reducing the number of resident cells inside of the biofilm. To prove evidence for our hypothesis, we analyzed the biofilm structure using CLSM, which compared the control group (without extract) and co-culture with extract group at different incubation times $(0,8,16,24 \mathrm{~h})$, as shown in Figure 4. The images were taken as Z-stacks, which included seven images in each stack in three different areas. Five parameters (biomass, average thickness, rough coefficient, surface to biovolume ratio, and maximum thickness) were analyzed using the COMSTAT program. The maximum thickness was reduced compared with the control at $16 \mathrm{~h}(\mathrm{p}$-value $=0.053)$. The biofilm structure was disturbed in the presence of the extract, which was clearly observed with CLSM.

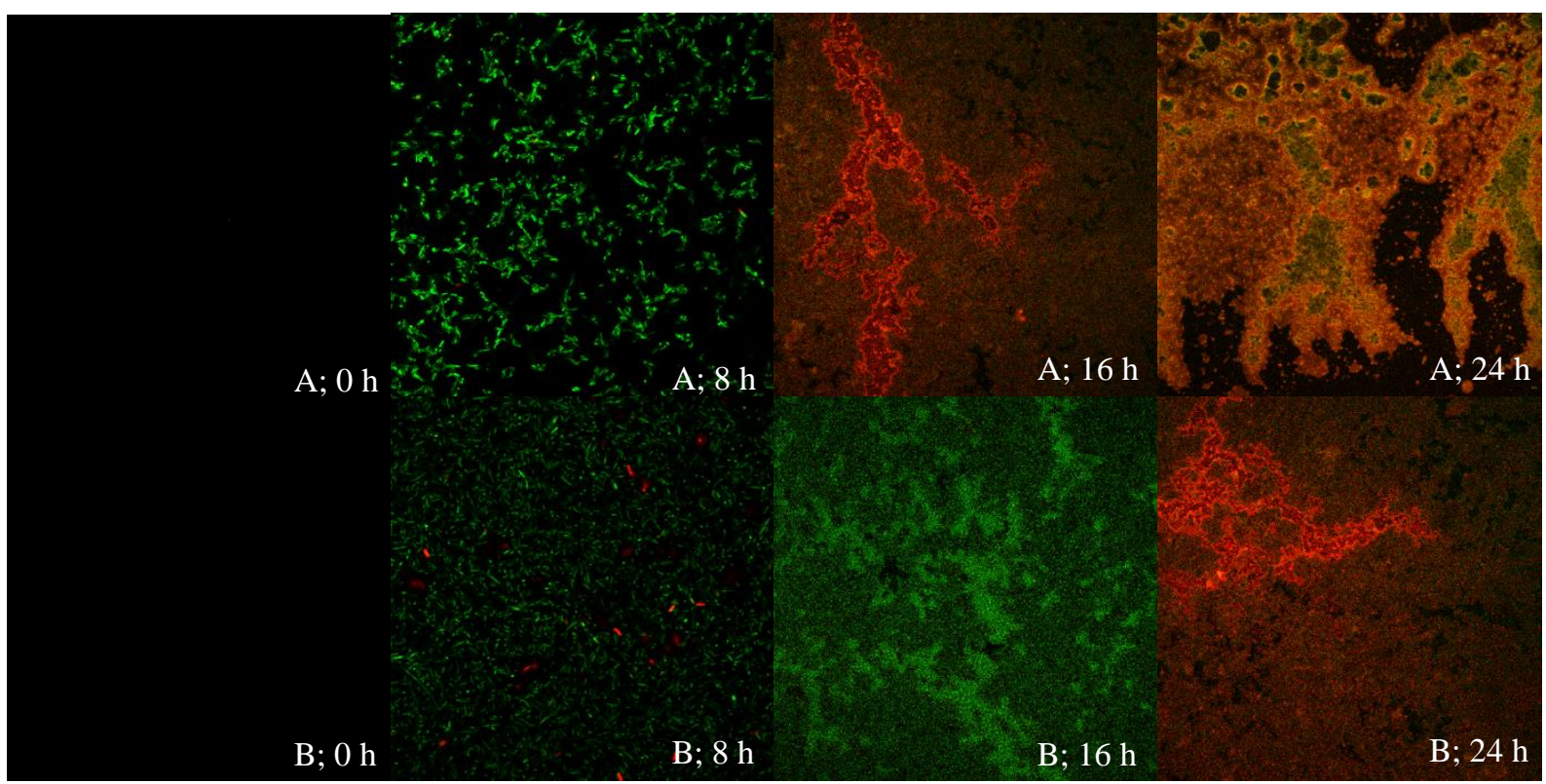

Figure 4: Confocal scanning laser microscope (CLSM) images of $P$. aeruginosa 50122 biofilm formations that were grown in the absence (A) and presence of $32 \mu \mathrm{g} / \mathrm{mL}$ mulberry leaf extract (B). The biofilms were labeled with Live/Dead (Syto9/PI) stain at 0, 8, 16, and $24 \mathrm{~h}$ incubation times.

\section{DISCUSSION}

Pseudomonas aeruginosa is a serious cause of health illnesses in many countries. These bacteria have adapted to survive under stressful conditions and can persist in the presence of antibiotics. The mechanisms that are utilized to survive under these stressful conditions include acquired antibiotic resistance genes, target changes, and efflux pumps to reduce the antibiotic 
level in the cells. One of the mechanisms of biofilm production involves secreting exopolysaccharides (slime) to protect resident cells inside the biofilm from antibiotics, host immune responses and the environment. Notably, this secretion causes antibiotics to penetrate biofilms slowly or incompletely, which can lead to non-specific resistance to all antimicrobial agent types. Moreover, biofilm communities may have more than one type of organism; therefore, the exchange of antibiotic resistance genes can occur at any time. Many $P$. aeruginosa antibiotics resistance mechanisms can turn pathogens into very challenging bacteria. New therapeutic strategies have been suggested to destroy biofilm formation, which would disrupt bacterial communication signals and utilize optimized antibiotics based on resistance issues. Alternative treatments include plant medicine, which include natural compounds that were found to affect biofilms, such as cranberry, garlic, galangal, and others. The mulberry leaf is a traditional herb and is used as a medicine in many Asian countries. This herb has many phytochemical substances, including antioxidants, that reduce LDL oxidation and blood sugar. In this study, we focused on the effects of the mulberry leaf extract on $P$. aeruginosa biofilms. Almost all of the observed clinical P. aeruginosa isolates (136 strains) formed biofilms (79\%) according to the SBF index. Most of the positive strains had strong biofilm production activity (74\%). These strains might be important with regard to public health, whereby suitable antibiotic usage is of concern. Bacterial biofilms are involved in a wide spectrum of diseases and are of significant concern ${ }^{12}$. If device-associated biofilm infections are serious, then chronic infections, transferred antibiotic resistance ability and persistent bacterial cells are also involved ${ }^{13,33}$. These biofilm producer infections are difficult to clear with typical antibiotic therapies. Thus, the biofilm-producing activity should be determined from clinical isolates for specific therapies. Here, we show that the mulberry leaf extract activity decreased the number of biofilm producers from nearly $80 \%$ to $50 \%$, and most notably, the numbers of strong biofilm producers were reduced in half. The effect on the $24 \mathrm{~h}-$ biofilm formations by the extracts were appropriately examined, and we found that $32 \mu \mathrm{g} / \mathrm{mL}$ of the ether mulberry leaf extract could sufficiently reduce the amount of biofilm and bacterial cell survival. While cranberry juice has been shown to affect uropathogenic E. coli biofilms ${ }^{34}$, cranberry extract can also inhibit adhesion and co-aggregation of numerous dental bacteria 35. Recently, cranberry A-type proanthocyanidins (PACs) were shown to significantly disturb the $P$. aeruginosa swarming motility, which affected the $P$. aeruginosa biofilm aggregation ${ }^{36}$. In addition to cranberry, blueberry, tea and other medicinal plants also presented anti-biofilm properties ${ }^{37,38}$. There is also evidence that cranberry extract can be used for protecting against urinary tract infections (UTI) in a pilot study ${ }^{39}$. The combination of potential medicinal plant extracts with antibiotics was shown in an in vitro $C$. albicans study with eugenol and cinnamaldehyde, which also showed synergy with fluconazole ${ }^{40}$. The analyzed co-culture 
biofilm structures following extract incubation showed that the substratum coverage of the biofilms was rough and disrupted; however, the changes in these factors were not statistically significant $(\mathrm{P}>0.05)$. Interestingly, the mucoid colonies could survive better than the nonmucoid colonies. The combination of gentamicin and the ether mulberry leaf extract (512 $\mu \mathrm{g} / \mathrm{mL}$ ) reduced the MIC from 8 to $2 \mu \mathrm{g} / \mathrm{mL}$, even though the mulberry leaf extract did not display any antibacterial activity. A study regarding the flavonoid dietary compounds in citrus showed that these compounds acted as Gram-negative bacteria quorum-sensing inhibitors ${ }^{41}$. Recently, a flavonoid that was isolated from the Moringa oleifera seed coat was evaluated against Staphylococcus aureus, Pseudomonas aeruginosa and Candida albicans biofilm formations ${ }^{42}$. The only report to provide evidence for dental pathogens included the mulberry leaf extract (Morus alba) compound 1-deoxynojirimycin (DNJ), which was shown to have antiadherence effects against Streptococcus mutans ${ }^{22}$. It seems likely that the DNJ had an effect on the $S$. mutans biofilm, which caused the mushroom cap and stalk of the architecture to disappear ${ }^{22}$. Several interesting active mulberry leaf extract compounds were found, including quercetin (which exhibited strong antioxidant capabilities) ${ }^{43}$. These compounds also presented anti-S. aureus biofilm activities ${ }^{44}$. In this investigation, the mulberry leaf extract was valuable in providing further information regarding the significant active compounds that cause biofilm reduction. There is limited literature regarding anti-Gram-negative bacteria biofilm agents, particularly Pseudomonas aeruginosa, which is well known to form biofilms. This report sheds light on the effects of the mulberry leaf, which is a cultivable and popular herb in Thailand and other Asian countries, on this pathogen's biofilm. The results in this study show that mulberry extracts have potential anti-biofilm activity with an ability to reduce biofilm formation. This study should provide an alternative strategy for effective treatments of deadly infection caused by the most common drug resistant bacteria, P. aeruginosa. Further study should isolate and identify the constituents that exhibit these anti-biofilm properties.

\section{CONCLUSION}

The results showed the effect of mulberry leaf extract on Pseudomonas aeruginosa biofilm by disrupting the biofilm structure which observed in the biofilm architecture. Although the mulberry extract had no evidence of microbicidal activity, it showed the impact on the process of biofilm production. It is one of the virulence factors of $P$. aeruginosa that promotes the spread of drug resistance by protecting resident cells in the structure of biofilm.

\section{ACKNOWLEDGEMENT}

This study was supported by the Thailand Research Fund (TRF) and the Office of the Higher Education Commission and Faculty of Allied Health Sciences, Chulalongkorn University. 


\section{REFERENCES}

1. Christensen KL, Holman RC, Steiner CA, Sejvar JJ, Stoll BJ, Schonberger LB. Infectious disease hospitalizations in the United States. Clin Infect Dis 2009;49:102535.

2. Davoudi AR, Najafi N, Hoseini Shirazi M, Ahangarkani F. Frequency of bacterial agents isolated from patients with nosocomial infection in teaching hospitals of Mazandaran University of Medical Sciences in 2012. Caspian J Intern Med 2014;5:22731.

3. Gaynes R, Edwards JR. Overview of nosocomial infections caused by gram-negative bacilli. Clin Infect Dis 2005;41:848-54.

4. Vidal F, Mensa J, Almela M, et al. Epidemiology and outcome of Pseudomonas aeruginosa bacteremia, with special emphasis on the influence of antibiotic treatment. Analysis of 189 episodes. Arch Intern Med 1996;156:2121-6.

5. Danchaivijitr S, Judaeng T, Sripalakij S, Naksawas K, Plipat T. Prevalence of nosocomial infection in Thailand 2006. J Med Assoc Thai 2007;90:1524-9.

6. Hsueh PR, Chen WH, Luh KT. Relationships between antimicrobial use and antimicrobial resistance in Gram-negative bacteria causing nosocomial infections from 1991-2003 at a university hospital in Taiwan. Int J Antimicrob Agents 2005;26:463-72.

7. Defez C, Fabbro-Peray P, Bouziges N, et al. Risk factors for multidrug-resistant Pseudomonas aeruginosa nosocomial infection. J Hosp Infect 2004;57:209-16.

8. Lambert PA. Mechanisms of antibiotic resistance in Pseudomonas aeruginosa. J R Soc Med 2002;95 Suppl 41:22-6.

9. Mah TF, Pitts B, Pellock B, Walker GC, Stewart PS, O'Toole GA. A genetic basis for Pseudomonas aeruginosa biofilm antibiotic resistance. Nature 2003;426:306-10.

10. Stewart PS. Mechanisms of antibiotic resistance in bacterial biofilms. Int $\mathbf{J}$ Med Microbiol 2002;292:107-13.

11. Fux CA, Costerton JW, Stewart PS, Stoodley P. Survival strategies of infectious biofilms. Trends Microbiol 2005;13:34-40.

12. Romling U, Kjelleberg S, Normark S, Nyman L, Uhlin BE, Akerlund B. Microbial biofilm formation: a need to act. J Intern Med 2014;276:98-110.

13. Taylor PK, Yeung AT, Hancock RE. Antibiotic resistance in Pseudomonas aeruginosa biofilms: towards the development of novel anti-biofilm therapies. J Biotechnol 2014;191:121-30.

14. Sharma G, Rao S, Bansal A, Dang S, Gupta S, Gabrani R. Pseudomonas aeruginosa biofilm: potential therapeutic targets. Biologicals 2014;42:1-7. 
15. Singh SB, Barrett JF. Empirical antibacterial drug discovery--foundation in natural products. Biochem Pharmacol 2006;71:1006-15.

16. Zeng Z, Qian L, Cao L, et al. Virtual screening for novel quorum sensing inhibitors to eradicate biofilm formation of Pseudomonas aeruginosa. Appl Microbiol Biotechnol 2008;79:119-26.

17. Jakobsen TH, van Gennip M, Phipps RK, et al. Ajoene, a sulfur-rich molecule from garlic, inhibits genes controlled by quorum sensing. Antimicrob Agents Chemother 2012;56:2314-25.

18. Zafar MS, Muhammad F, Javed I, et al. White mulberry (Morus alba): a brief phytochemical and pharmacological evaluations account. Int J Agric Biol 2013;15:61220.

19. Wang W, Zu Y, Fu Y, Efferth T. In vitro antioxidant and antimicrobial activity of extracts from Morus alba L. leaves, stems and fruits. Am J Chin Med 2012;40:349-56.

20. Nam S, Jang HW, Shibamoto T. Antioxidant activities of extracts from teas prepared from medicinal plants, Morus alba L., Camellia sinensis L., and Cudrania tricuspidata , and their volatile components. J Agric Food Chem 2012;60:9097-105.

21. Hikino H, Mizuno T, Oshima Y, Konno C. Isolation and hypoglycemic activity of moran A, a glycoprotein of Morus alba root barks. Planta Med 1985:159-60.

22. Islam B, Khan SN, Haque I, Alam M, Mushfiq M, Khan AU. Novel anti-adherence activity of mulberry leaves: inhibition of Streptococcus mutans biofilm by 1deoxynojirimycin isolated from Morus alba. J Antimicrob Chemother 2008;62:751-7.

23. Clinical and Laboratory Standards Institute. M7-A10: Methods for Dilution Antimicrobial Susceptibility Tests for Bacteria That Grow Aerobically. Wayne, PA: Clinical and Laboratory Standards Institute; 2009.

24. Pillai SK, Moellering Jr. RK, Eliopoulos GM. Antimicrobial combinations. In: Lorian V, ed. Antibiotics in Laboratory Medicine. 5th ed. Philadelphia: Lippincott Williams \& Wilkins; 2005:366-416.

25. Naves P, del Prado G, Huelves L, et al. Measurement of biofilm formation by clinical isolates of Escherichia coli is method-dependent. J Appl Microbiol 2008;105:585-90.

26. Ceri H, Olson ME, Stremick C, Read RR, Morck D, Buret A. The Calgary Biofilm Device: new technology for rapid determination of antibiotic susceptibilities of bacterial biofilms. J Clin Microbiol 1999;37:1771-6.

27. Heydorn A, Nielsen AT, Hentzer M, et al. Quantification of biofilm structures by the novel computer program COMSTAT. Microbiology 2000;146 (Pt 10):2395-407. 
28. Stepanovic S, Vukovic D, Hola V, et al. Quantification of biofilm in microtiter plates: overview of testing conditions and practical recommendations for assessment of biofilm production by staphylococci. APMIS 2007;115:891-9.

29. Koh SF, Tay ST, Puthucheary SD. Colonial morphotypes and biofilm forming ability of Burkholderia pseudomallei. Trop Biomed 2013;30:428-33.

30. Sudjana AN, Carson CF, Carson KC, Riley TV, Hammer KA. Candida albicans adhesion to human epithelial cells and polystyrene and formation of biofilm is reduced by sub-inhibitory Melaleuca alternifolia (tea tree) essential oil. Med Mycol 2012;50:863-70.

31. Liesse Iyamba JM, Seil M, Devleeschouwer M, Takaisi Kikuni NB, Dehaye JP. Study of the formation of a biofilm by clinical strains of Staphylococcus aureus. Biofouling 2011;27:811-21.

32. Wolska K, Kot B. Twitching motility activity, biofilm formation, and genetic typing for clinical isolates of Pseudomonas aeruginosa by random amplified DNA PCR. Acta Microbiol Immunol Hung 2013;60:313-28.

33. Macia MD, Perez JL, Molin S, Oliver A. Dynamics of mutator and antibiotic-resistant populations in a pharmacokinetic/pharmacodynamic model of Pseudomonas aeruginosa biofilm treatment. Antimicrob Agents Chemother 2011;55:5230-7.

34. Di Martino P, Agniel R, Gaillard JL, Denys P. Effects of cranberry juice on uropathogenic Escherichia coli in vitro biofilm formation. J Chemother 2005;17:5635.

35. Babu J, Blair C, Jacob S, Itzhak O. Inhibition of Streptococcus gordonii metabolic activity in biofilm by cranberry juice high-molecular-weight component. J Biomed Biotechnol 2012;2012:590384.

36. Ulrey RK, Barksdale SM, Zhou W, van Hoek ML. Cranberry proanthocyanidins have anti-biofilm properties against Pseudomonas aeruginosa. BMC Complement Altern Med 2014;14:499.

37. Zhang H, Zhou W, Zhang W, et al. inhibitory effects of citral, cinnamaldehyde, and tea polyphenols on mixed biofilm formation by foodborne Staphylococcus aureus and Salmonella enteritidis. J Food Prot 2014;77:927-33.

38. Zimmer KR, Blum-Silva CH, Souza AL, et al. The antibiofilm effect of blueberry fruit cultivars against Staphylococcus epidermidis and Pseudomonas aeruginosa. J Med Food 2014;17:324-31.

39. Cai T, Caola I, Tessarolo F, et al. Solidago, orthosiphon, birch and cranberry extracts can decrease microbial colonization and biofilm development in indwelling urinary 
catheter: a microbiologic and ultrastructural pilot study. World J Urol 2014;32:100714.

40. Khan MS, Ahmad I. Antibiofilm activity of certain phytocompounds and their synergy with fluconazole against Candida albicans biofilms. J Antimicrob Chemother 2012;67:618-21.

41. Vikram A, Jayaprakasha GK, Jesudhasan PR, Pillai SD, Patil BS. Suppression of bacterial cell-cell signalling, biofilm formation and type III secretion system by citrus flavonoids. J Appl Microbiol 2010;109:515-27.

42. Onsare JG, Arora DS. Antibiofilm potential of flavonoids extracted from Moringa oleifera seed coat against Staphylococcus aureus, Pseudomonas aeruginosa and Candida albicans. J Appl Microbiol 2015;118:313-25.

43. Kim GN, Jang HD. Flavonol content in the water extract of the mulberry (Morus alba L.) leaf and their antioxidant capacities. J Food Sci 2011;76:C869-73.

44. Lee JH, Park JH, Cho HS, Joo SW, Cho MH, Lee J. Anti-biofilm activities of quercetin and tannic acid against Staphylococcus aureus. Biofouling 2013;29:491-9.

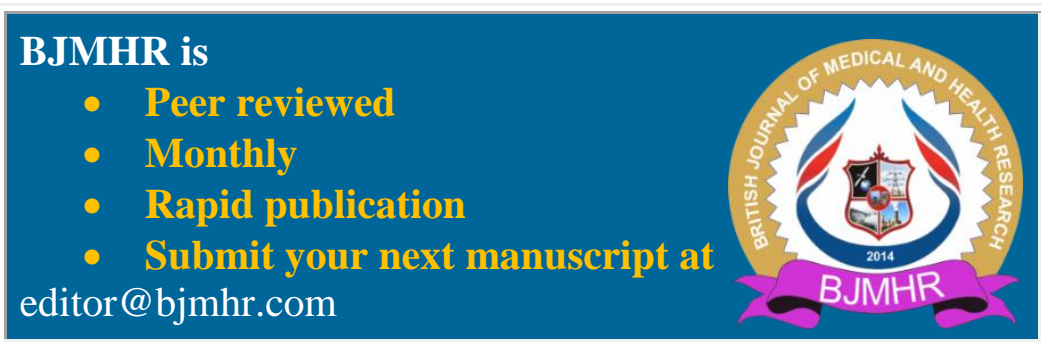

